\title{
Central Auditory Processing and Cognitive Functions in Children
}

\author{
Nadja Cristina Furtado Back ${ }^{10}$ Ana Chrystina de Souza Crippa ${ }^{2}$ \\ Tatiana Izabelle Jaworski de Sá Riechi ${ }^{30}$ Liliane Desgualdo Pereira ${ }^{4}$ \\ 1 Postgraduate program in psychology, Universidade Federal do \\ Address for correspondence Nadja Cristina Furtado Back, \\ Paraná, Curitiba, PR, Brazil \\ 2 Department of pediatrics, Universidade Federal do Paraná Hospital \\ Phonoaudiologist, Master in Psychology, Universidade Federal do \\ Paraná, Programa de Pós-graduação em Psicologia, Universidade \\ Federal do Paraná, Praça Santos Andrade, 50, sala 217-B Curitiba, \\ de Clínicas, Curitiba, PR, Brazil \\ 3 Psychology department, Universidade Federal do Paraná, Curitiba, \\ PR 80020-300, Brazil (e-mail: nadjaback.nb@gmail.com).
}

PR, Brazil

${ }^{4}$ Phonoaudiology department, Universidade Federal do Estado de

São Paulo, São Paulo, SP, Brazil

Int Arch Otorhinolaryngol 2022;26(1):e20-e31.

\begin{abstract}
Keywords

- auditory perception

- attention

- memory

- intelligence

- executive functions
\end{abstract}

Introduction Nowadays, there is no consensus on whether central auditory processing disorder is a primary or a secondary deficit to other cognitive deficits. A better understanding of the association between cognitive functions and central auditory skills may help elucidate this dilemma.

Objective To investigate possible associations between auditory abilities and cognitive functions in schoolchildren.

Methods Fifty-eight schoolchildren, aged between 8 years and 0 months old and 11 years and 11 months old, who underwent the following tests: masking level difference, gaps in noise, pitch pattern sequence test, dichotic digits test, sustained auditory attention ability test, Wechsler intelligence scale for children - IV, junior Hayling test, five digits test, and behavior rating inventory of executive function.

Results Significant correlations were found between the hearing ability of temporal resolution and executive functions, temporal ordering/sequencing, binaural integration and separation, and sustained auditory attention, operational memory, inhibitory control, and cognitive flexibility; binaural integration was also associated with intelligence. The statistically significant positive correlation found between the ability of binaural interaction and the components of emotional control and behavior regulation of the behavior rating inventory of executive function was unexpected.

Conclusion The associations identified reinforce the complexity of the tasks involved in the evaluation of central auditory processing and the need for multidisciplinary evaluation for the differential diagnosis of auditory processing disorder. Confirmation of the presence or absence of comorbidities between different disorders allows directing the therapeutic behaviors and reducing the impact of possible auditory and/or cognitive deficits in the different daily life situations of children. received

February 12, 2020

accepted

October 12, 2020

published online

February 19, 2021
DOI https://doi.org/ 10.1055/s-0040-1722158. ISSN 1809-9777.

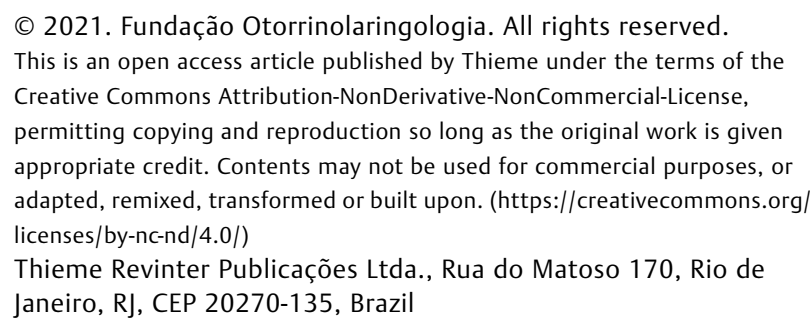

(c) 2021. Fundação Otorrinolaringologia. All rights reserved. This is an open access article published by Thieme under the terms of the Creative Commons Attribution-NonDerivative-NonCommercial-License, permitting copying and reproduction so long as the original work is given appropriate credit. Contents may not be used for commercial purposes, or adapted, remixed, transformed or built upon. (https://creativecommons.org/ licenses/by-nc-nd/4.0/) Thieme Revinter Publicações Ltda., Rua do Matoso 170, Rio de Janeiro, RJ, CEP 20270-135, Brazil 


\section{Introduction}

Central auditory processing (CAP) refers to a series of processes and mechanisms that occur from sound being picked up by the outer ear to being interpreted in the auditory cortex, and involves the following skills: sound localization and lateralization; discrimination and recognition of acoustic stimulus differences; temporal processing (resolution, masking, integration, and sequence) and auditory background; and perception of the target stimulus in situations with competitive signals. ${ }^{1}$ The mechanisms involved in auditory processing are: binaural interaction, dichotic listening, monoaural low redundancy, and temporal processing. ${ }^{2}$

Binaural interaction is the way the two ears work together for the purpose of locating and lateralizing auditory stimuli, lowering the threshold by masking, detecting acoustic signals in noisy environments, and binaural fusion. ${ }^{3}$ Dichotic listening consists of the simultaneous presentation of different stimuli in both ears, which causes suppression of ipsilateral auditory pathways and predominance of contralateral auditory pathways. ${ }^{4,5}$ Tests with dichotic listening tasks assess binaural integration skills (ability to hear and understand different stimuli at the same time), binaural separation (when it is possible to ignore one of the stimuli and direct attention to the other simultaneous stimulus), and are sensitive to dysfunctions or injuries of interhemispheric and intrahemispheric connections of the right hemisphere and the left hemisphere. ${ }^{6}$ The monoaural low redundancy mechanism occurs when there is degradation of the acoustic signal reducing extrinsic redundancy (phonemic and contextual speech cues) requiring intrinsic redundancy (repetition of acoustic signal analyses along the auditory pathway) to perform auditory closure of missing information allowing understanding of information. ${ }^{7}$ Temporal processing refers to the way nonverbal patterns (rhythm, intonation, emphasis, and intervals) of auditory information are perceived, associated, and interpreted. ${ }^{6}$ It has four subcategories: temporal ordering and sequence, temporal resolution, temporal integration, and temporal masking. There are no clinically viable measures yet to assess integration and temporal masking. ${ }^{8}$

The difficulty in the perception of auditory information along with the central auditory nervous system, evidenced by the poor performance in one or more of the mechanisms mentioned above, characterizes central auditory processing disorder (CAPD). Alterations of higher functions, such as language, attention, and memory, are not included in the definition of CAPD, but may coincide. ${ }^{1}$ Therefore, a multidisciplinary assessment may be necessary for differential diagnosis, identifying the primary deficit and the presence of comorbidities. ${ }^{1,2,5,9-15}$

There is no consensus in the literature about the nature of CAPD, and many discussions have taken place in an attempt to clarify the diagnosis. Some researchers believe that CAPD could only occur when there is a specific auditory deficit and that the tests used to assess CAP show more global responses regarding general intelligence, language comprehension, attention, memory, and executive functions. ${ }^{16-21}$ Other authors, supported by studies of auditory and cognitive neurophysiology, state that considering the specific modality as a diagnostic criterion is untenable from a neurophysiological point of view, since the central auditory nervous system is complex and responds to stimulation of nonauditory areas. ${ }^{1,4,9,10,22,23}$

The complexity of the processes that occur in the central auditory nervous system requires knowledge of the auditory and/or cognitive skills required to perform the behavioral tests used to assess CAP. Hearing disability, manifested by the difficulty of understanding auditory information, can leave cognitive, social, and emotional functions vulnerable. ${ }^{24}$ Functions such as attention, perception, memory, language, and executive functions form human cognition, and acting in an integrated manner, allow individuals to function well in different contexts according to the requirements of the environment. ${ }^{25}$ The tests developed to evaluate these auditory processes are complex and involve tasks that may require the action of executive functions, such as attention and working memory. ${ }^{26}$

Executive functions are defined as a set of cognitive processes that guide behavior to achieve goals. ${ }^{27-29}$ There is no consensus on which functions are involved and how their constructs work, but Diamond ${ }^{30}$ proposes one of the most accepted models, which considers executive functions to have three basic skills: inhibition (self-control and interference control), working memory, and cognitive flexibility. Other skills, such as planning, reasoning, and problem-solving, are complex and emerge from the core. The prefrontal cortex is the main region involved in executive functioning, but it also depends on the activity distributed in different neural circuits, ${ }^{29}$ with the involvement of various brain areas, including temporal lobe regions. Therefore, changes in regions that affect executive functioning may also affect auditory skills, ${ }^{22}$ and difficulties in the perception of auditory stimuli may limit the use of an executive function, preventing the generalization of strategic listening behaviors in different situations. ${ }^{26}$

Studies have been conducted to understand the relationship between CAP and other higher mental functions, ${ }^{15,31-41}$ but there are only a few studies involving the relationship between CAP and executive functions.

Considering that CAPD can coexist with other cognitive and language disorders, the present paper aims to describe the association between auditory skills and cognitive functions to better understand this relationship, which may contribute to health and education, enabling more accurate diagnoses and optimized interventions, reducing the impact of hearing and/ or cognitive impairment on the daily life of individuals.

\section{Methodology}

The present study was conducted on Centro de Neuropediatria do Hospital de Clínicas (CENEP-HC) da Universidade Federal do Paraná (UFPR) and Centro de Psicologia Aplicada (CPA) da UFPR and was approved by the Research Ethics Committee/UFPR Health Sciences Sector, as Coordinating Center (Opinion 2.675.148) and by the Research Ethics Committee/HC, as a coparticipant institution (Opinion 3.037.057).

The convenience sample consists of 58 children of both genders, aged between 8 years and 0 months old and 11 years and 11 months old, regularly enrolled in the Elementary 
School of the Julia Amaral Di Lenna Municipal School $(n=36)$, and/or attended at the outpatient clinic CENEP-HC $(n=22)$, and who are enrolled in elementary school in other Curitiba and metropolitan area municipal public schools.

During recruitment, 71 children were included considering the following criteria: regularly enrolled between the $3^{\text {rd }}$ and $6^{\text {th }}$ grade of elementary school, in municipal public schools of Julia Amaral di Lenna $(n=46)$ and/or attended at the clinic of Neuropediatric of CENEP-HC $(n=25)$; absence of diagnosis of neurodevelopmental disorder (attentiondeficit / hyperactivity disorder, autistic spectrum disorder and language disorder); free and informed consent form (ICF) signed by parents or guardians; informed consent form signed by the child (ICFC).

According to the exclusion criteria, 13 participants were excluded: conductive hearing loss $(n=3)$; intellectual disability (IQ $<70)(n=1)$; oral language impairment (phonetic/phonological disorders) $(n=1)$; did not complete both assessment steps $(n=8)$.

The final sample consisted of 58 children, 33 males (53.9\%) and 25 females (43.1\%), with an average age of 9 years and 7 months old (standard deviation $[S D]=1.16$ ). The evaluated children attend between the $3^{\text {rd }}$ and $6^{\text {th }}$ grade of elementary school. The complaint of difficulty in school was reported during anamnesis by $46.6 \%$ of the parents or guardians of the children in the sample. - Fig. 1 demonstrates the data collection process.

The assessment protocol consisted of 2 parts, auditory and cognitive assessment, composed of the following instruments: tonal audiometry threshold hearing thresholds search at frequencies from 250 to $8,000 \mathrm{~Hz}$ and speech reception threshold (SRT); tympanometry and acoustic reflex research; masking level difference ${ }^{42}(\mathrm{MLD})$, pure tone $(500 \mathrm{~Hz})$ hearing threshold determination in the presence of narrowband noise under two conditions: homophobic - when there is the same phase relationship for tone and noise in both ears (SoNo) - and antiphrastic - when noise is in the same phase in both ears, and pure tone is in inverted phase in one ear $(\mathrm{S} \pi \mathrm{No})$. The intensity used is $45 \mathrm{dBNS}$, and the result analysis is performed based on the difference between the SoNo and SזNo thresholds. Values $>9 \mathrm{~dB}$ are considered appropriate. Gaps in noise ${ }^{43}$ (GIN), monaural presentation of series with segments of 6 seconds of broadband noise. In each segment, zero to three intervals of silence or gap can occur. The gap duration can be presented in $2,3,4,5,6,8,10,12,15$, and 20 seconds. The intensity used is $50 \mathrm{dBNS}$. Values $\leq 8$ milliseconds are considered adequate. Pitch pattern sequence ${ }^{44}$ (PPS), 200 milliseconds 3-tone sequences, with intervals of 10 milliseconds between them; between sequences, the interval is 150 milliseconds. The tones are presented binaurally at the frequencies of $880 \mathrm{~Hz}$ and $1,122 \mathrm{~Hz}$, representing bass and treble sounds. The sequence of stimuli should be named according to the frequencies shown. The intensity used is $50 \mathrm{dBNS}$. From the values described by Schochat et al, ${ }^{45}$ the reference values are defined as normality criteria for both ears: 8 years: $47 \% ; 9 / 10$ years: $62 \%$; $11 / 12$ years: $69 \%$; dichotic digits ${ }^{46}(D D)$, presentation of 20 pairs of digits ( 1 to 9 syllables), 2 simultaneous digits in each ear. Dichotic digits is performed in two steps: binaural integration, in which the four digits presented must be repeated, and binaural separation, where only the digits presented in the requested ear are repeated. It is performed at an intensity of $50 \mathrm{dBNS}$. Performance is considered adequate according to the reference values for each age group described in the test manual. ${ }^{47}$ Sustained auditory attention ability test ${ }^{48}$ (SAAAT) is a continuous performance test (CPT), which requires the maintenance of vigilance and the identification of a previously determined target stimulus. It consists of the simultaneous presentation in both ears of a list of 21 recorded monosyllabic words that are repeated and rearranged randomly, forming a list of 100 words, including the 20 occurrences of the target word "no," presented 6 times without interruption ( 1 word per second) - totaling 600 monosyllabic words. The individuals should raise their hand each time they hear the target word "no." The intensity used for the stimulus presentation is $\mathbf{5 0}$ dBNS. The reference values by age range described in the test application are used for the analysis of the results. The junior Hayling test ${ }^{49}(\mathrm{JHI})$ (adapted for Brazilian Portuguese), consists of a two-step task, in which the subject must complete sentences in which the last word is missing. In part $\mathrm{A}$, one must use the word that completes the sentence consistently. Part B uses a word that does not have a meaningful relation to the sentence, inhibiting the dominant response, looking for a word that has no relation to the syntactic and semantic context of the sentence. For the classification are considered the percentiles described in the test manual. The five digit test ${ }^{50}$ (FDT), a nonverbal instrument that uses 5 quantities (numbers from 1 to 5) as simple recurrent cognitive units within tasks of increasing difficulty. It consists of four parts: reading, counting, choosing, and toggling; the first two measure automatic and straightforward processes, and the last two measure more complex processes. It allows a brief and straightforward assessment of cognitive processing speed, ability to focus, refocus attention, and ability to deal with interference. For the classification, the percentiles described in the test manual are considered. Wechsler children's intelligence scale ${ }^{51}$ (WISC) IV, a clinical instrument that aims to assess children's intellectual capacity and problem-solving process. It provides information on the total intelligence coefficient (IQ) and four indices: verbal comprehension (VCI), perceptual organization (POI), working memory (WMI), and processing speed (PSI). To meet the objectives of the present research, WMI and PSI were analyzed for the evaluation of executive functions, and total IQ for intelligence classification. For classification purposes, composite scores are considered as described in the manual. Behavior rating inventory of executive function ${ }^{52}$ (BRIEF), parent version, a questionnaire consisting of 86 questions that parents must grade from a scale (never, sometimes, consistently) to the frequency of occurrence of problem behavior in the child. It evaluates the behavior of executive functions of children aged between 5 and 18 years old in the family environment. The classification of the results is performed according to the norms of the application manual, and indices $>65$ are considered indicative of changes in the evaluated indices. The questionnaire was answered by a parent or guardian who accompanied the child on the day of the assessment. The experimental version provided and authorized by Mello (Universidade 


\section{Central auditory processing and cognitive functions in children}

\section{Figure}

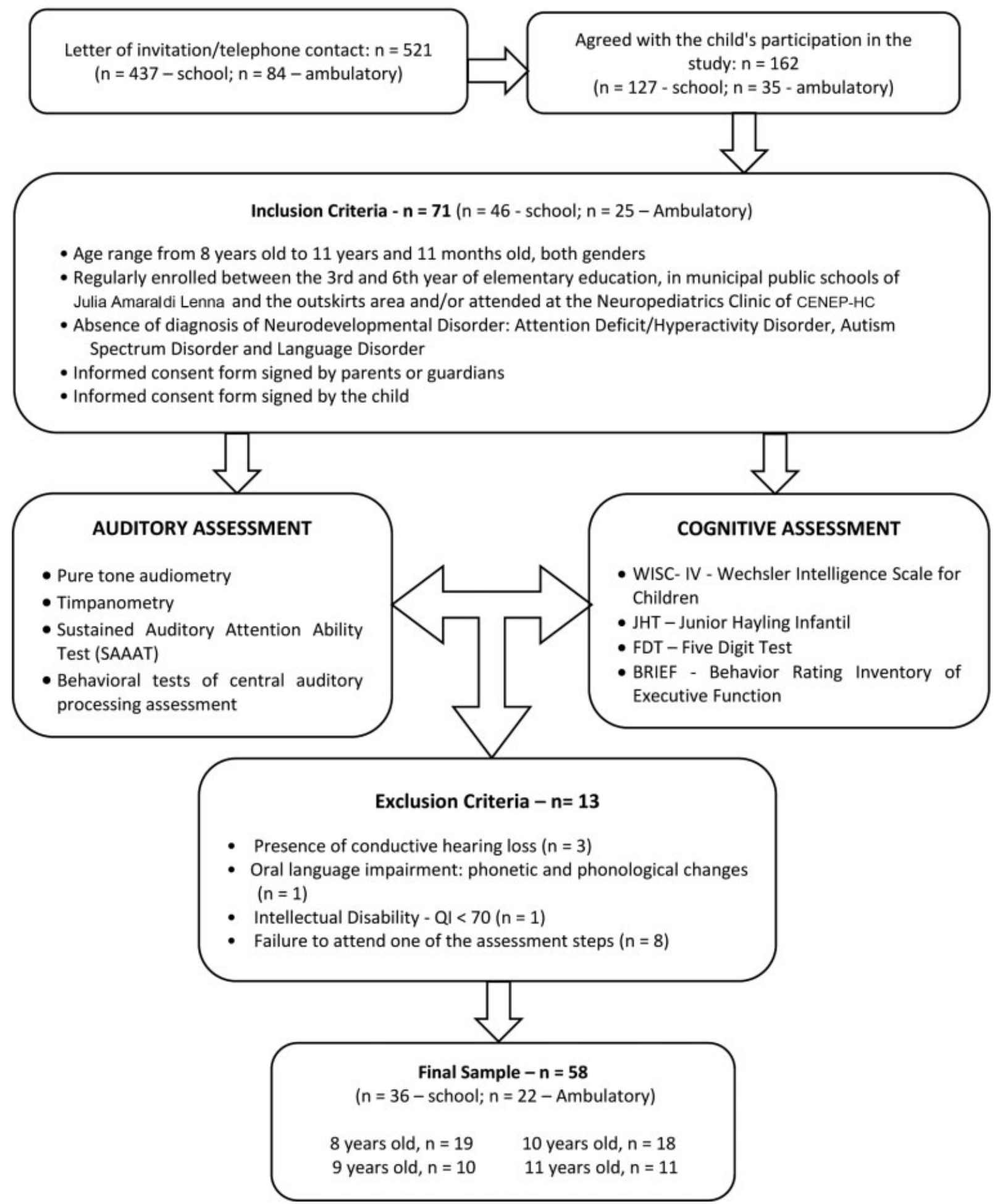

Fig. 1 Flowchart of the data collection process.

Federal do Estado de São Paulo [UNIFESP, in the Portuguese acronym) was used; Carin, Miranda, and Bueno. ${ }^{52}$

The children were submitted to the assessment protocol applied individually with a total duration of $\sim 3$ hours and 30 minutes, divided into 2 days and in different places. The psychological tests were performed and appraised by a psychologist of the Postgraduate program in psychology of UFPR team.

For the hearing tests, performed in the CENEP-HC, the following equipment was used: a) São Luiz brand acoustic 
booth; b) Clinical Beta two-channel audiometer, with headphones TDH-39 and cushion MX-41, coupled to the compact disc (CD) of a DELL computer; c) Interacoustics brand middle ear analyzer, model AZ-7, with TDH-39 earphone, MX-41 cushion, with probe tone $220 \mathrm{~Hz}$ at $70 \mathrm{~dB}$; d) $\mathrm{CD}$ with recording of MLD tests, ${ }^{53}$ GIN and PPS (CD purchased directly from the author Frank Musiek), ${ }^{54,55}$ and DD, ${ }^{47} \mathrm{f}$ ) download of SAAAT test audio file available to registered speech therapists at http://thaas1.fob.usp.br. (Sustained Auditory Attention Ability Test - THAAS. Faculdade de Odontologia de Bauru, Universidade de São Paulo. São Paulo. Brazil).

The data were distributed to descriptive analyzes of mean, median, minimum values, maximum values, SD, and frequency analyzes. The use of the Shapiro-Wilk test indicated that some variables are not standard. Therefore, the association between hearing tests and cognitive tests was verified with the Spearman correlation test. The data were analyzed using IBM SPSS Statistics for Windows, version 22.0 (IBM Corp. Armonk, NY ,USA). ${ }^{56}$ The significance level of 0.05 was set to determine whether the correlation between variables is significant.

\section{Results}

The values obtained in the hearing tests with the general sample and with the participants grouped by age group are described in - Table 1. Data are presented according to the measurement used for each test: MLD, decibel (dB); GIN, milliseconds (ms), PPS, and DD hit percentage (\%).

When analyzing - Table $\mathbf{1}$, the difference between the minimum and maximum values in PPS and DD is verified, both in the task of binaural integration and binaural separation, demonstrating the great variability of children's performance in these tests, regardless of age. One participant (10 years old) failed to answer the MLD test adequately, and another participant ( 8 years old) failed to respond to the GIN. Both participants had difficulty understanding the tests, presenting random answers that could not be considered.
The hearing tests are classified according to the reference values described for each test, and $63.2 \%$ of the students presented an adequate performance in the MLD test, and 89.5\% in the GIN test. The PPS was the test with the most significant number of underperforming participants (72.4\%). In DD, the left ear performed worse in $36.2 \%$ of participants in the binaural integration task and in $31 \%$ in the binaural separation task.

The auditory skills evaluated were appropriate to the age group in $22.4 \%$ of the participants. For classification purposes, the students who presented underperformance for the age group in $\geq 2$ hearing tests (58.6\%) were considered as having CAPD. When the change was identified in only 1 test, it was classified as evidence of CAPD (19\%).

The data that characterize cognitive performance are presented in - Table 2, with information from the general sample, and in -Table $\mathbf{3}$, with the participants grouped by age. It is observed that the median of the participants in the total IQ of the WISC-IV test was 101 points, with the most significant difference in performance in the 10-year-old participants (44 points between the minimum and maximum value), and the lowest in the 11-year-old age group (29 points). In the SAAAT test, the total number of errors varied between 2 and 70 errors, mainly in the age groups of 8 and 9 years old. In the JHT, the variability in response time, especially in part B of the test, was also abundant in all age groups, with time differences between 18 and 150 seconds. In the FDT, the participants took more time to perform the flexibility tasks, with time varying between 11 and 109 seconds; in the age group of 11 years old, the participants had faster responses with a median of 24 seconds. The BRIEF responses indicate $T$ scores with a median of $\sim 55$ points on all items assessed. The number of participants in the BRIEF test is lower $(n=52)$, as 3 parents did not answer the questionnaire, and 3 questionnaires were excluded from the sample due to a high rate of inconsistency and negative responses.

Regarding the classification in cognitive tests, it is evident that $\sim 90 \%$ of the participants have a mean score for the

Table 1 Performance of students in hearing tests in the general sample and by age group

\begin{tabular}{|c|c|c|c|c|c|c|c|c|c|}
\hline \multicolumn{2}{|l|}{ Variable } & \multirow[t]{2}{*}{ MLD (dB) } & \multicolumn{2}{|c|}{$\begin{array}{l}\text { GIN } \\
\text { (ms) }\end{array}$} & \multirow[t]{2}{*}{ PPS (\%) } & \multicolumn{2}{|c|}{$\begin{array}{l}\text { DD Integration } \\
(\%)\end{array}$} & \multicolumn{2}{|c|}{$\begin{array}{l}\text { DD Separation } \\
(\%)\end{array}$} \\
\hline & & & RE & LE & & RE & LE & RE & LE \\
\hline \multirow[t]{2}{*}{ General sample $(n=58)$} & median & 10 & 5 & 6 & 33 & 95 & 92 & 92 & 91 \\
\hline & $\min / \max$ & $4 / 14$ & $4 / 15$ & $4 / 15$ & $10 / 86$ & $50 / 100$ & $40 / 100$ & $35 / 100$ & $47 / 100$ \\
\hline \multirow{2}{*}{$\begin{array}{l}8 \text { years old } \\
(n=18)\end{array}$} & median & 10 & 5 & 6 & 30 & 92 & 87 & 90 & 85 \\
\hline & $\min / \max$ & $6 / 12$ & $4 / 10$ & $4 / 10$ & $10 / 63$ & $50 / 100$ & $40 / 97$ & $50 / 100$ & $57 / 100$ \\
\hline \multirow{2}{*}{$\begin{array}{l}9 \text { years old } \\
(n=10)\end{array}$} & median & 11 & 6 & 6 & 30 & 95 & 86 & 90 & 85 \\
\hline & $\min / \max$ & $6 / 14$ & $5 / 10$ & $5 / 12$ & $20 / 83$ & $62 / 100$ & $62 / 100$ & $35 / 97$ & $47 / 100$ \\
\hline \multirow{2}{*}{$\begin{array}{l}10 \text { years old } \\
(n=18)\end{array}$} & median & 8 & 5 & 5 & 33 & 97 & 97 & 95 & 93 \\
\hline & $\min / \max$ & $4 / 12$ & $4 / 15$ & $4 / 15$ & $16 / 80$ & $72 / 100$ & $65 / 100$ & $50 / 100$ & $67 / 100$ \\
\hline \multirow[t]{2}{*}{11 years old $(n=11)$} & median & 10 & 5 & 6 & 46 & 100 & 97 & 92 & 92 \\
\hline & $\min / \max$ & $6 / 14$ & $4 / 8$ & $4 / 6$ & $23 / 86$ & $90 / 100$ & $85 / 100$ & $67 / 100$ & $77 / 100$ \\
\hline
\end{tabular}

Abbreviations: dB, decibel; DD, digit dichotic; GIN, gaps In noise; LE, left ear; max, maximum; min, minimum; MLD, masking level difference test; ms, milliseconds; $n$, number; PPS, pitch pattern sequence; RE, right ear. 
Table 2 Performance of students in the instruments that assess cognitive functions, general sample $(n=58)$

\begin{tabular}{|c|c|c|c|c|c|}
\hline & Variable & $\mathbf{n}$ & Minimum & Maximum & Median \\
\hline \multirow[t]{5}{*}{ WISC-IV } & $\mathrm{VCl}$ & 58 & 82 & 138 & 104 \\
\hline & $\mathrm{POI}$ & 58 & 75 & 130 & 103 \\
\hline & WMI & 58 & 71 & 123 & 97 \\
\hline & PSI & 58 & 74 & 118 & 97 \\
\hline & IQ & 58 & 80 & 124 & 101 \\
\hline \multirow[t]{2}{*}{ SAAAT } & Total Errors & 58 & 2 & 70 & 17 \\
\hline & DS & 58 & -2 & 11 & 2 \\
\hline \multirow[t]{2}{*}{ JHT } & B Part & 58 & 18 & 150 & 38 \\
\hline & Error Category & 58 & 3 & 27 & 12 \\
\hline \multirow[t]{2}{*}{ FDT } & Inhibition & 58 & 11 & 88 & 38 \\
\hline & Flexibility & 58 & 11 & 109 & 43 \\
\hline \multirow[t]{3}{*}{ BRIEF } & Behavior Regulation & 52 & 42 & 77 & 54 \\
\hline & Metacognition & 52 & 33 & 80 & 56 \\
\hline & Global Executive Composition & 52 & 37 & 77 & 56 \\
\hline
\end{tabular}

Abbreviations: BRIEF, behavior rating inventory of executive function; DS, decreasing surveillance; FDT, five digit test; JHT, junior Hayling test; $\mathrm{n}$, number; POI, perceptual organization index; PSI, processing speed index; SAAAT, sustained auditory attention ability test; TIQ, total intelligence quotient; $\mathrm{VCI}$, verbal comprehension index; WISC-IV, Wechsler intelligence scale for children; WMI, working memory index.

Table 3 Performance of students in the instruments that assess cognitive functions by age group

\begin{tabular}{|c|c|c|c|c|c|c|c|c|c|c|c|c|}
\hline \multirow[t]{2}{*}{ Variable } & \multicolumn{3}{|c|}{8 years old } & \multicolumn{3}{|c|}{9 years old } & \multicolumn{3}{|c|}{10 years old } & \multicolumn{3}{|c|}{11 years old } \\
\hline & $\mathrm{n}$ & $\min / \max$ & med & $\mathbf{n}$ & $\min / \max$ & med & n & $\min / \max$ & med & $\mathrm{n}$ & $\min / \max$ & med \\
\hline \multicolumn{13}{|l|}{ WISC-IV } \\
\hline $\mathrm{VCl}$ & 19 & $82 / 128$ & 104 & 10 & $90 / 138$ & 108 & 18 & $82 / 121$ & 102 & 11 & $91 / 113$ & 104 \\
\hline $\mathrm{POI}$ & 19 & $86 / 126$ & 102 & 10 & $90 / 118$ & 107 & 18 & $75 / 130$ & 101 & 11 & $79 / 126$ & 108 \\
\hline WMI & 19 & $77 / 123$ & 94 & 10 & $74 / 106$ & 97 & 18 & $71 / 118$ & 97 & 11 & $85 / 118$ & 100 \\
\hline PSI & 19 & $83 / 115$ & 97 & 10 & $86 / 100$ & 95 & 18 & $80 / 115$ & 95 & 11 & $74 / 118$ & 100 \\
\hline IQ & 19 & $83 / 119$ & 102 & 10 & $84 / 122$ & 103 & 18 & $80 / 124$ & 99 & 11 & $90 / 119$ & 98 \\
\hline \multicolumn{13}{|l|}{ SAAAT } \\
\hline TE & 19 & $5 / 70$ & 23 & 10 & $11 / 55$ & 17 & 18 & $3 / 35$ & 15 & 11 & $2 / 35$ & 10 \\
\hline DS & 19 & $1 / 7$ & 3 & 10 & $0 / 7$ & 3 & 18 & $-2 / 6$ & 3 & 11 & $-1 / 11$ & 0 \\
\hline \multicolumn{13}{|l|}{ JHT } \\
\hline B Part & 19 & $18 / 150$ & 56 & 10 & $27 / 123$ & 37 & 18 & $18 / 134$ & 40 & 11 & $23 / 108$ & 38 \\
\hline Error Categ. & 19 & $4 / 25$ & 12 & 10 & $3 / 26$ & 12 & 18 & $3 / 19$ & 9 & 11 & $3 / 27$ & 14 \\
\hline \multicolumn{13}{|l|}{ FDT } \\
\hline Inhib. & 19 & $11 / 88$ & 25 & 10 & $26 / 55$ & 43 & 18 & $13 / 62$ & 31 & 11 & $21 / 69$ & 35 \\
\hline Flex. & 19 & $37 / 109$ & 43 & 10 & $22 / 65$ & 51 & 18 & $11 / 92$ & 40 & 11 & $14 / 44$ & 24 \\
\hline \multicolumn{13}{|l|}{ BRIEF } \\
\hline BR & 18 & $42 / 77$ & 55 & 9 & $44 / 74$ & 54 & 16 & $42 / 72$ & 49 & 9 & $58 / 67$ & 59 \\
\hline Metacog. & 18 & $33 / 80$ & 54 & 9 & $46 / 70$ & 53 & 16 & $39 / 75$ & 52 & 9 & $41 / 76$ & 57 \\
\hline GEC & 18 & $33 / 77$ & 55 & 9 & $46 / 70$ & 56 & 16 & $40 / 72$ & 49 & 9 & $42 / 74$ & 60 \\
\hline
\end{tabular}

Abbreviations: BR, behavior regulation; BRIEF, behavior rating inventory of executive function; DS, decreasing surveillance; Error categ., error category; FDT, five digit test; Flex., flexibility; GEC, global executive composition; Inhib., Inhibition; JHT, junior Hayling test; max, maximum; med, median; Metacog., metacognition; min, minimum; n, number; POI, perceptual organization index; PSI, processing speed index; TE, total errors; SAAAT, sustained auditory attention ability test; TIQ, total intelligence quotient; VCI, verbal comprehension index; WISC-IV, Wechsler intelligence scale for children; WMI, working memory Index. 
indexes evaluated in the WISC-IV, and the WMI presented the most significant number of participants with inferior performance $(5.2 \%)$, and the POI with superior performance (10.3\%). Not borderline or much higher scores were evidenced in this test. In the JHT test, $\sim 30 \%$ of the students presented a borderline performance in all indexes evaluated in the test, mainly in part B (32.8\%) and in the error category (37.9\%). The data obtained in the FDT test show that 60.3 and $44.8 \%$ of students had, respectively, percentiles of cognitive flexibility and inhibition, with performance classified as average. The percentiles obtained for inhibition were classified as borderline in $22.4 \%$ of the participants and as lower in $27.6 \%$. For flexibility, the rating was 8.6 and $19 \%$, respectively. In the SAAAT test, the total errors were adequate in $75.9 \%$, and the decrease in vigilance in $96.6 \%$ of the students. Among the types of errors, inattention was observed in $44.8 \%$ of participants and impulsiveness in $20.7 \%$. The classification in the BRIEF indicates that 70 to $88 \%$ of the students do not present difficulties in the executive functions investigated in the inventory, according to their parents' perception. However, the data show that $\sim 30 \%$ of the students have difficulty in working memory.
- Table 4 shows the estimated correlation measures between each of the variables for the entire sample, and - Table 5 shows the study performed according to the age group. In the estimation of the correlations, the following scores of each auditory test were used: MLD, dB; GIN, ms; PPS and DD, percentage of correct answers. Percentile scores for the WISC-IV, JHT and FDT indexes, gross scores for SAAAT and $\mathrm{T}$ score indexes for BRIEF were considered for instruments that assess cognitive functions.

- Tables $\mathbf{4}$ and $\mathbf{5}$ show the following correlations between auditory skills and cognitive functions: binaural interaction (MLD) and executive functions (BRIEF); temporal resolution (GIN), processing speed (WISC-IV), inhibitory control (JHT and BRIEF) and planning (BRIEF); temporal ordering/sequence (PPS), working memory (WISC-IV and BRIEF), sustained auditory attention (SAAAT), inhibitory control (JHT), cognitive flexibility (FDT) and metacognition (BRIEF); binaural integration (DD), intelligence (WISC-IV), sustained auditory attention (SAAAT), inhibitory control (JHT and FDT) and cognitive flexibility (FDT); binaural separation (DD), sustained auditory attention (SAAAT), cognitive flexibility (FDT) and inhibitory control (FDT).

Table 4 Correlation between behavioral tests that assess central auditory processing and cognitive function tests in schoolchildren

\begin{tabular}{|c|c|c|c|c|c|c|c|c|c|}
\hline & \multirow[t]{2}{*}{ Variable } & \multirow[t]{2}{*}{ MLD } & \multicolumn{2}{|l|}{ GIN } & \multirow[t]{2}{*}{ PPS } & \multicolumn{2}{|c|}{ DD - Integration } & \multicolumn{2}{|c|}{ DD - Separation } \\
\hline & & & RE & LE & & RE & LE & RE & LE \\
\hline \multirow[t]{5}{*}{ WISC-IV } & $\mathrm{VCl}$ & -0.058 & -0.217 & -0.054 & 0.200 & $0.272^{*}$ & 0.142 & -0.132 & -0.099 \\
\hline & POI & -0.033 & -0.063 & -0.022 & 0.179 & $0.393^{* *}$ & 0.198 & 0.094 & 0.026 \\
\hline & WMI & 0.048 & -0.172 & -0.050 & $0.337^{*}$ & $0.407^{* *}$ & 0.159 & 0.178 & 0.105 \\
\hline & PSI & 0.098 & $-0.262^{*}$ & 0.044 & 0.007 & 0.213 & 0.153 & 0.030 & -0.004 \\
\hline & IQ & -0.006 & -0.233 & -0.013 & 0.235 & $0.424^{* *}$ & 0.220 & 0.067 & 0.011 \\
\hline \multirow[t]{3}{*}{ SAAAT } & Total Errors & -0.072 & -0.030 & 0.032 & $-0.513^{* *}$ & $-0.259^{*}$ & $-0.363^{* *}$ & $-0.381^{* *}$ & $-0.299^{*}$ \\
\hline & Inattention & -0.043 & -0.106 & -0.009 & $-0.482^{* *}$ & $-0.260^{*}$ & $-0.314^{*}$ & $-0.271^{*}$ & -0.258 \\
\hline & Impulsiveness & -0.041 & 0.123 & 0.008 & $-0.297^{*}$ & -0.067 & -0.157 & $-0.446^{* *}$ & $-0.263^{*}$ \\
\hline \multirow[t]{3}{*}{ JHT } & B Part - TE & -0.098 & -0.086 & -0.070 & 0.023 & 0.202 & $0.272^{*}$ & -0.075 & -0.059 \\
\hline & TB / TA & -0.103 & -0.193 & $-0.352^{* *}$ & -0.001 & 0.153 & 0.210 & -0.154 & -0.087 \\
\hline & Error Category & 0.123 & -0.157 & -0.141 & $0.293^{*}$ & $0.311^{*}$ & $0.324^{*}$ & 0.181 & 0.175 \\
\hline \multirow[t]{2}{*}{ FDT } & Inhibition & 0.066 & 0.136 & 0.035 & 0.214 & $0.347^{* *}$ & 0.196 & 0.299* & 0.054 \\
\hline & Flexibility & 0.152 & 0.048 & 0.008 & $0.383^{* *}$ & $0.338^{* *}$ & 0.226 & $0.432^{* *}$ & 0.137 \\
\hline \multirow[t]{7}{*}{ BRIEF } & Inhibition & 0.257 & 0.012 & $0.359^{* *}$ & -0.136 & -0.077 & -0.089 & -0.056 & -0.107 \\
\hline & $E C$ & $0.358^{*}$ & 0.017 & 0.202 & -0.134 & -0.037 & -0.018 & 0.056 & 0.029 \\
\hline & BR & $0.337^{*}$ & 0.000 & 0.253 & -0.163 & -0.057 & -0.055 & -0.010 & -0.057 \\
\hline & WM & 0.091 & -0.022 & 0.156 & $-0.341^{*}$ & -0.256 & -0.215 & -0.081 & -0.161 \\
\hline & Planning & 0.098 & 0.040 & $0.289^{*}$ & -0.260 & -0.180 & -0.129 & -0.078 & 0.057 \\
\hline & Metacognition & 0.074 & 0.050 & 0.253 & $-0.313^{*}$ & -0.182 & -0.138 & -0.101 & -0.079 \\
\hline & GEC & 0.215 & 0.000 & 0.269 & -0.256 & -0.117 & -0.082 & -0.031 & -0.041 \\
\hline
\end{tabular}

Abbreviations: BR, behavior regulation; BRIEF, behavior rating inventory of executive function; DD, digit dichotic; EC, emotional control; FDT, five digit test; GEC, global executive composition; GIN, gaps in noise; JHT, junior Hayling test; LE, left ear; MLD, masking level difference test; POI, perceptual organization index; PPS, pitch pattern sequence; PSI, processing speed index; RE, right ear; SAAAT, sustained auditory attention ability test; TA, time part A; TB, time part B; TE, total errors; TIQ, total intelligence quotient; VCl, verbal comprehension index; WISC-IV, Wechsler intelligence scale for children; WM, working memory; WMI, working memory index. Note: ${ }^{*} p \leq 0.05 ;{ }^{* *} p \leq 0.01$. 
Central Auditory Processing and Cognitive Functions in Children Back et al. 27

Table 5 Correlation between behavioral tests that assess central auditory processing and cognitive function tests in schoolchildren by age group

\begin{tabular}{|c|c|c|c|c|c|c|c|c|c|}
\hline \multicolumn{2}{|c|}{ Variable } & \multirow[t]{2}{*}{ MLD } & \multicolumn{2}{|l|}{ GIN } & \multirow[t]{2}{*}{ PPS } & \multicolumn{2}{|c|}{ DD - Integration } & \multicolumn{2}{|c|}{ DD - Separation } \\
\hline & & & RE & LE & & RE & LE & RE & LE \\
\hline \multirow[t]{15}{*}{8 years old } & WISC-IV & & & & & & & & \\
\hline & POI & -0.276 & 0.170 & 0.251 & 0.095 & $0.496^{*}$ & 0.354 & 0.205 & 0.337 \\
\hline & WMI & 0.064 & -0.045 & 0.103 & 0.209 & $0.523^{*}$ & 0.106 & 0.329 & 0.014 \\
\hline & PSI & $0.466^{*}$ & -0.128 & 0.225 & -0.037 & 0.057 & -0.146 & 0.382 & 0.001 \\
\hline & IQ & -0.043 & 0.006 & 0.187 & 0.148 & $0.531^{*}$ & 0.266 & 0.353 & 0.195 \\
\hline & SAAAT & & & & & & & & \\
\hline & Total errors & -0.090 & 0.226 & 0.128 & -0.350 & 0.018 & $-0.492^{*}$ & -0.086 & -0.333 \\
\hline & Impulsiveness & -0.333 & 0.204 & 0.061 & $-0.710^{* *}$ & -0.306 & $-0.489^{*}$ & $-0.704^{* *}$ & -0.423 \\
\hline & JHT & & & & & & & & \\
\hline & B Part - TE & 0.055 & -0.269 & -0.065 & 0.158 & 0.189 & $0.490^{*}$ & 0.038 & 0.192 \\
\hline & Error Category & 0.324 & -0.117 & -0.161 & $0.462^{*}$ & 0.141 & $0.562^{*}$ & 0.318 & 0.267 \\
\hline & FDT & & & & & & & & \\
\hline & Flexibililty & $0.573^{*}$ & -0.318 & -0.278 & 0.215 & 0.260 & 0.199 & 0.372 & 0.016 \\
\hline & BRIEF & & & & & & & & \\
\hline & WM & $0.520^{*}$ & -0.082 & 0.124 & -0.003 & 0.088 & 0.102 & 0.397 & 0.191 \\
\hline \multirow[t]{7}{*}{9 years old } & Total errors & 0.147 & 0.271 & 0.440 & $-0.635^{*}$ & -0.568 & $-0.706^{*}$ & -0.488 & -0.466 \\
\hline & FDT & & & & & & & & \\
\hline & Flexibility & 0.147 & -0.065 & -0.141 & 0.620 & $0.634^{*}$ & $0.900^{* *}$ & $0.729^{*}$ & 0.400 \\
\hline & BRIEF & & & & & & & & \\
\hline & Inhibition & 0.478 & 0.214 & 0.155 & -0.067 & -0.311 & -0.120 & -0.360 & $-0.867^{* *}$ \\
\hline & $\mathrm{BR}$ & $0.751^{*}$ & -0.100 & 0.309 & -0.313 & -0.259 & -0.072 & -0.102 & -0.383 \\
\hline & Planning & 0.189 & 0.365 & 0.543 & $-0.830^{*}$ & $-0.752^{*}$ & -0.380 & -0.610 & -0.151 \\
\hline \multirow[t]{13}{*}{10 years old } & PSI & -0.038 & $-0.566^{*}$ & -0.224 & -0.011 & 0.394 & $0.478^{*}$ & 0.048 & 0.040 \\
\hline & IQ & -0.058 & -0.364 & -0.027 & 0.430 & $0.502^{*}$ & 0.459 & 0.230 & 0.194 \\
\hline & SAAAT & & & & & & & & \\
\hline & Total errors & -0.231 & -0.184 & -0.254 & $-0.520^{*}$ & -0.067 & -0.145 & -0.372 & -0.205 \\
\hline & Inattention & -0.214 & -0.098 & -0.211 & $-0.614^{* *}$ & -0.165 & -0.147 & -0.420 & -0.358 \\
\hline & JHT & & & & & & & & \\
\hline & $\mathrm{TB} / \mathrm{TA}$ & -0.376 & $-0.492^{*}$ & $-0.612^{* *}$ & -0.201 & 0.067 & 0.299 & -0.278 & -0.305 \\
\hline & Error Category & -0.436 & -0.434 & -0.346 & 0.348 & 0.374 & $0.534^{*}$ & 0.118 & 0.318 \\
\hline & FDT & & & & & & & & \\
\hline & Inhibition & 0.175 & 0.187 & 0.367 & $0.596^{* *}$ & $0.470^{*}$ & 0.244 & $0.599^{* *}$ & 0.258 \\
\hline & Flexibility & 0.216 & 0.225 & 0.272 & $0.551^{*}$ & 0.415 & 0.053 & $0.664^{* *}$ & 0.259 \\
\hline & BRIEF & & & & & & & & \\
\hline & WM & -0.298 & -0.343 & -0.358 & $-0.632^{* *}$ & -0.241 & -0.006 & $-0.508^{*}$ & -0.355 \\
\hline \multirow[t]{7}{*}{11 years old } & POI & 0.360 & -0.216 & -0.351 & -0.189 & 0.431 & 0.233 & -0.441 & $-0.751^{* *}$ \\
\hline & IQ & 0.265 & -0.101 & -0.133 & 0.304 & 0.390 & 0.030 & -0.376 & $-0.614^{*}$ \\
\hline & JHT & & & & & & & & \\
\hline & B Part - TE & 0.028 & 0.319 & 0.091 & -0.179 & 0.129 & -0.303 & $-0.792^{* *}$ & $-0.731^{*}$ \\
\hline & BRIEF & & & & & & & & \\
\hline & Inhibition & 0.503 & -0.004 & $0.704^{*}$ & -0.197 & -0.111 & -0.043 & 0.403 & 0.225 \\
\hline & $\mathrm{EC}$ & 0.159 & 0.159 & $0.713^{*}$ & -0.577 & -0.258 & 0.047 & 0.324 & 0.191 \\
\hline
\end{tabular}


Table 5 (Continued)

\begin{tabular}{|c|l|l|l|l|l|l|l|l|l|}
\hline \multicolumn{2}{|c|}{ Variable } & MLD & \multicolumn{2}{l|}{ GIN } & \multicolumn{2}{l|}{ PPS } & \multicolumn{2}{l|}{ DD - Integration } & \multicolumn{2}{l|}{ DD - Separation } \\
\cline { 3 - 10 } \multicolumn{2}{|c|}{} & & RE & LE & & RE & LE & RE & LE \\
\hline \multirow{3}{*}{} & BR & 0.159 & 0.159 & $\mathbf{0 . 6 8 1 ^ { * }}$ & -0.611 & -0.157 & 0.158 & 0.277 & 0.178 \\
\cline { 2 - 10 } & Metacognition & -0.291 & 0.388 & 0.389 & $-0.727^{*}$ & -0.438 & -0.009 & 0.189 & 0.004 \\
\cline { 2 - 10 } & GEC & -0.053 & 0.309 & 0.519 & $-0.774^{*}$ & -0.253 & 0.141 & 0.227 & 0.085 \\
\hline
\end{tabular}

Abbreviations: BR, behavior regulation; BRIEF, behavior rating inventory of executive function; DD, digit dichotic; EC, emotional control; FDT, five digit test; GEC, global executive composition; GIN, gaps in noise; IQ, total intelligence quotient; JHT, junior Hayling test; LE, left ear; MLD, masking level difference test; POI, perceptual organization index; PPS, pitch pattern sequence; PSI, processing speed index; RE, right ear; SAAAT, sustained auditory attention ability test; TA, time part A; TB, time part B; TE, total errors; VCl, verbal comprehension index; WISC-IV, Wechsler intelligence scale for children; WM, working memory; WMI, working memory index.

Note: ${ }^{*} p \leq 0.05 ;{ }^{* *} p \leq 0.01$.

Due to the different scoring criteria used in the hearing and cognitive tests, negative correlations were expected. Some tests indicate better performance when their rates are low and others when their rates are high. As in the negative correlation found between PPS and SAAAT $(\mathrm{p}=$ $0.513 ; \mathrm{p}=<0.001$ ), indicating the association of the occurrence of the lowest number of errors in the SAAAT subtests with the highest number of correct answers in the PPS. However, the positive correlation identified between MLD and BRIEF indicates that when there is a better perception of the difference in the level of masking in MLD, there are higher rates of emotional control and behavior regulation. High levels in BRIEF suggest the inefficiency of the executive functions.

\section{Discussion}

In the last decades, many debates have been taking place among researchers about the interference of cognitive performance in hearing tests, $1,4,10,16-18,20-22,57$ and there is a growing number of studies that seek to understand the association between these functions, with memory and attention functions being the most studied. ${ }^{32-34,36,39-41}$

The present research aims to verify the possible associations between auditory skills (binaural interaction, temporal resolution, temporal ordering and sequence, binaural integration and binaural separation) and cognitive functions (intelligence, sustained auditory attention, working memory, inhibitory control, and flexibility) in schoolchildren.

Statistical analyses demonstrate the moderate association between sustained auditory attention and auditory skills of temporal order/sequence, integration, and binaural separation, corroborating with the data obtained in other studies that related different CPTs that evaluate sustained auditory and/or visual attention and DD,,$^{32,33,35,39,41}$ and also with other auditory tests, such as Staggered Spondaic Word (SSW) that was not used in this study. ${ }^{34}$ However, Riccio et al. ${ }^{37}$ and Stavrinos et al. ${ }^{40}$ did not find this correlation. In the present research, as in other studies, ${ }^{33,35,39-41}$ no associations were identified between sustained auditory attention and the MLD and GIN tests. Sustained auditory attention ability showed stronger and more significant correlations with hearing tests than the other correlations. This result is essential, and difficulties of sustained hearing attention should be considered during the application of hearing tests that evaluate CAP.

The temporal resolution hearing ability evaluated using GIN shows a significant correlation with executive functions: inhibitory control, processing speed, and planning. The task required in GIN requires the subject to respond to interruptions that occur within seconds during a continuous stimulus of white noise. The hypothesis for this association with the inhibitory control function, which was the most statistically significant correlation, is the need to control the impulse to respond to the stimulus even when there is no interval, waiting for stimulus interruption to occur. Self-control is an aspect of inhibitory control in which it is necessary to resist stimuli (external or internal) in order not to act impulsively or prematurely. ${ }^{30}$ Processing speed and planning may also be required in the task, as stimulus interruption may not occur, or may occur between 1 and 3 times with each presentation, with brief time intervals ( 2 to 20 seconds), requiring quick and planned responses. The literature does not report similar analyzes involving these tests, which makes it impossible to compare these findings. Studies using the GIN test have made associations with auditory and/or visual attention, as previously reported, and some studies have found possible associations with intelligence using tests that assess nonverbal $\mathrm{IQ}^{33,35,41}$ but found no significant correlations.

The ordering ability/temporal sequence evaluated with the task of naming the PPS, in addition to presenting the association with sustained auditory attention, demonstrated association with working memory, cognitive flexibility and inhibitory control evidenced in correlation with phrase categorization errors in the JHT, that is, by evocation patterns and strategies used to inhibit automatic response during the test. ${ }^{47}$ Such associations may be justified by the presence of three stimuli that differ in frequency patterns, which must be memorized and associated with acute/severe concepts (requiring activation of previously stored information recall areas for subsequent naming). ${ }^{34}$ Cognitive flexibility that involves shifting or shifting the focus of information, action, or thought processing to suit environmental requirements, $27,29,30,58,59$ is also required, since the sequence of stimuli presented in the PPS changes with each presentation. 
The data found in the present study also show the statistically significant correlation between working memory and dichotic listening (DD). Understanding that shortterm memory involves the temporary storage of information, while working memory implies a combination of storage and manipulation, in the presence of two or more simultaneous stimuli, the participation of the central executive component, which acts as a data supervisor, is required. ${ }^{60}$ Thus, it is inferred that the task required in DD, dichotic listening, involves both types of memory since two stimuli are presented simultaneously in each ear, requiring the central executive component's participation in the maintenance of these stimuli so that they can be repeated accordingly. Maerlender et al. ${ }^{61}$ found a strong association between DD and short-term memory, and a more modest association with working memory, reinforcing this hypothesis. Other studies also point to associations between working memory and hearing skills, although using different tests to assess working memory, having found significant correlations with DD, ${ }^{31,32}$ DD and PPS, ${ }^{39,41,62}$ PPS and SSW. ${ }^{34}$ Murphy et al. ${ }^{35}$ did not find significant associations between temporal processing tests (PPS and GIN) and working memory tests.

In addition to WMI, other associations were identified between DD and intelligence indexes measured with WISCIV, such as total IQ POI, and VCI. Correlations are significant only for the right ear binaural integration task. The advantage of the right ear is because hemispheric areas of language expertise in most individuals are in the left hemisphere, ${ }^{63}$ and the functions required for the tasks involved in determining indices also involve the left hemisphere, which may justify the correlation found. Gyldenkærne et al. $^{33}$ and Tomlin et al. ${ }^{41}$ found significant correlations between left ear dichotic listening tasks in DD and nonverbal IQ tests. Other researches did not identify associations between nonverbal IQ and hearing skills. ${ }^{32,35,39}$ Weihing et al. ${ }^{64}$ found significant correlations between PPS and total WISC-IV IQ, but found no association with other WISC-IV indices. This association between WISC-IV, PPS, DD, and total IQ was also observed by Brenneman et al., ${ }^{31}$ who, by including individuals with language and/or cognitive deficits, identified a higher degree of association also with other WISC-IV indices, such as perceptual organization and working memory.

The DD was also associated with inhibitory control and cognitive flexibility. In the executive function model described by Diamond, ${ }^{30}$ inhibitory control involves self-regulation and interference control (selective attention), which may justify the findings, since the tasks involved in DD require divided attention (when repeating the four stimuli; two on each side) and directed attention (by repeating only the two stimuli presented in the right ear and then those in the left ear). Stavrinos et al. ${ }^{40}$ found significant correlations between tests that evaluate divided auditory attention and $\mathrm{DD}$, and recommend caution when using and analyzing this test in the CAP assessment battery due to the interference of attentional aspects evidenced in the results found in the research.

The positive and significant correlation evidenced between MLD, emotional control, and behavior regulation
(BRIEF) was unexpected, since it indicates that better responses are expected in MLD when there are higher levels of emotional control and behavior regulation in the inventory, indicating alteration of these components. Considering that emotional control is related to the impact of executive function problems on emotional expression as the individual controls his emotional responses, and that behavior regulation is also related to emotional modulation through appropriate inhibitory control, ${ }^{65}$ it can be inferred that the task required in performing MLD may not require these functions. Although the consulted literature did not show studies using this correlation, studies conducted with MLD associated with other cognitive functions, such as intelligence, attention, and memory, did not find significant correlations, ${ }^{33,39,41}$ showing that this test seems to suffer little interference from the cognitive functions. Further studies are needed for a better understanding of this association.

There is a growing body of literature aimed at understanding the nature of CAPD, but most studies are conducted with relatively small samples. The exception is the work of Moore et al., 57 who conducted a study of 1,469 schoolchildren aged between 6 and 11 years old with normal hearing who were randomly selected from schools in different regions of the United Kingdom. The results showed significant correlations between cognitive tests and tests that assess central auditory functions, and the conclusion was that CAPD is primarily a problem of attention, as poor performance in hearing tests was associated with a generalized attention deficit. However, the researchers used an unusual battery of tests to evaluate core auditory functions (frequency discrimination, backward masking, simultaneous masking, speech in noise testing), which precludes generalizing these results with other auditory tests that may require less attention. ${ }^{33}$

Considering the results of the present study, it is possible to state that cognitive functions, especially attention and executive functions (working memory, inhibitory control, and cognitive flexibility), are related to some tests that assess central auditory functions and may interfere with the performance of individuals during these tests. Stavrinos et al. ${ }^{40}$ suggest that the CAPD diagnostic criteria need to be reconsidered as they do not include cognitive diagnostic measures. Despite the small sample and weak to moderate associations, the data from the present research reinforce this statement and the recommendation of multidisciplinary assessment in the assessment of CAPD for differential diagnosis among other neurodevelopmental disorders, identifying the presence or absence of comorbidities., ${ }^{1,5,9-15}$ Research with larger samples and the use of different instruments to investigate cognition, especially executive functions, is necessary, since the literature is still scarce on the subject.

\section{Conclusion}

The associations evidenced in the present study between auditory skills and cognitive functions, although weak to moderate, notably demonstrate that the isolated interpretation of CAP tests can be difficult, since the interference of 
cognitive functions, especially sustained auditory attention and hearing impairments, is susceptible. Executive functions (working memory, inhibitory control, and cognitive flexibility) had the strongest correlations with the different hearing tests used. Thus, caution is suggested when interpreting the data obtained in the CAP assessment tests, considering the possible interferences of cognitive functioning.

Further research is needed to better understand the practical implications of the unexpected associations between binaural interaction auditory ability and emotional component executive functions (emotional control and behavior regulation), since no similar studies were found in the literature.

The results of the present study reinforce the need for multidisciplinary assessment, with an investigation of cognitive aspects, to better understand the hearing difficulties evidenced in the CAP tests, allowing the differential diagnosis, the optimization of the therapeutic intervention and the reduction of the impact of hearing deficits and/or cognitive disorders in schoolchildren.

Conflict of Interests

The authors have no conflict of interests to declare.

\section{References}

1 American Speech-Language-Hearing Association (ASHA) (Central) Auditory Processing Disorders. [Technical Report]. 2005. Accessed Feb, 15, 2019 at: http://www.asha.org/policy

2 Bellis TJ, Bellis JD. Central auditory processing disorders in children and adults. In: Aminoff MJ, Boller F, Swaab DF, (Series Eds.), Celesia GG, Hickok G, (Vol. Eds.). Handbook of clinical neurology - The human auditory system: fundamental organization and clinical disorders. Oxford: Elsevier; 2015:537-556

3 Mccullagh J, Bamiou D-E. Measures of binaural interaction. In: Musiek FE, Chermak GD (Eds.). Handbook of (central) auditory processing disorder: auditory neuroscience and diagnosis. San Diego: Plural; 2014:435-469

4 Hugdahl K, Helland T. Central auditory processing as seen from dichotic listening studies. In: Musiek FE, Chermak GD, (Eds.). Handbook of (central) auditory processing disorder: auditory neuroscience and diagnosis. San Diego: Plural; 2014:153-189

5 Musiek FE, Chermak GD. Auditory neuroscience and central auditory processing disorder: an overview. In: Musiek FE, Chermak GD (Eds.). Handbook of (central) auditory processing disorder: auditory neuroscience and diagnosis. San Diego: Plural; 2014:3-15

6 Alvarez AMMC, Sanchez ML, Carvalho IAM. - Neuroaudiologia e linguagem. In: Fuentes D, Malloy-Diniz LF, Camargo CHP, Cosenza RM (Orgs.). Neuropsicologia teoria e prática. Porto Alegre. Art Med; 2008:136-150

7 Krishnamurti S. Monaural low-redundancy speech tests. In: Musiek FE, Chermak GD, (Eds.). Handbook of (central) auditory processing disorder: auditory neuroscience and diagnosis. San Diego: Plural; 2014:349-367

8 Shinn JB. Temporal processing tests. In: Musiek FE, Chermak GD, (Eds.). Handbook of (central) auditory processing disorder: auditory neuroscience and diagnosis. San Diego: Plural; 2014: 405-434

9 American Academy of Audiology (AAA) Guidelines for the Diagnosis, Treatment and Management of Children and Adults with Central Auditory Processing Disorder. American Academy of Audiology, (August). 2010. Accessed February 15, 2019 at: https://audiology-web.s3.amazonaws.com/migrated/CAPD\% 20Guidelines\%208-2010.pdf_539952af956c79.73897613.pdf
10 Bellis TJ. The nature of central auditory processing disorder. In: Musiek FE, Chermak GD (Eds.). Handbook of (central) auditory processing disorder: auditory neuroscience and diagnosis. San Diego: Plural; 2014:211-230

11 Canadian Interorganizational Steering Group for Speech-Language Pathology and Audiology (CISG) Canadian guidelines on auditory processing disorder in children and adults: assessment and intervention. The Canadian Interorganizational Steering Group for Speech-Language Pathology and Audiology 2012. Accessed February 15, 2019 at: http://www.sac.oac.ca/sites/default/files/resources/Canadian-Guidelines-on-456Auditory-Processing-Disorder-in-Children-and-Adults-English-2012.pdf

12 Chermak GD, Bamiou D-E, Vivian Iliadou V, Musiek FE. Practical guidelines to minimise language and cognitive confounds in the diagnosis of CAPD: a brief tutorial. Int J Audiol 2017;56(07):499-506

13 Iliadou VV, Ptok M, Grech H, et al. A European perspective on auditory processing disorder-current knowledge and future research focus. Front Neurol 2017;8(622):1-7

14 Iliadou VV, Sirimanna T, Bamiou D-E. CAPD is classified in ICD-10 as H93.25 and hearing evaluation - not screening - should be implemented in children with verified communication and/or listening deficits. Am J Audiol 2016;25(04):368-370

15 de Wit E, van Dijk P, Hanekamp S, et al. Same or different: the overlap between children with auditory processing disorders and children with other developmental disorders: a systematic review. Ear Hear 2018;39(01):1-19

16 British Society of Audiology (BSA) Position Statement Auditory processing disorder. British Society of Audiology, (March), 1-9 2011. Accessed May, 22, 2019 at: http://www.thebsa.org.uk/wpcontent/uploads/2014/04/BSA_APD_PositionPaper_31March11_ FINAL.pdf

17 British Society of Audiology (BSA) Position Statement and Practice Guidance: Auditory processing disorder (APD). British Society of Audiology,(February), 5-192018. Accessed May, 22,2019 at: http:// www.thebsa.org.uk/wp-content/uploads/2018/09/Position-Statement-and-Practice-Guidance-APD-2018.pdf

18 Cacace AT, McFarland DJ. The importance of modality specificity in diagnosing central auditory processing disorder. Am J Audiol 2005;14(02):112-123

19 DeBonis DA. It is time to rethink central auditory processing disorder protocols for school-aged children. Am J Audiol 2015;24 (02):124-136

20 Moore DR. Editorial: auditory processing disorder. Ear Hear 2018; 39(04):617-620

21 Wilson WJ. Evolving the concept of APD. Int J Audiol 2018;57(04): 240-248

22 Bellis TJ. Assessment and management of central auditory processing disorders in the educational setting from science to practice. New York: Delmar Learning; 2003

23 Musiek FE, Bellis TJ, Chermak GD. Nonmodularity of the central auditory nervous system: implications for (central) auditory processing disorder. Am J Audiol 2005;14(02):128-138, discussion $143-150$

24 Kreisman NV, John AB, Kreisman BM, Hall JW, Crandell CC. Psychosocial status of children with auditory processing disorder. J Am Acad Audiol 2012;23(03):222-233, quiz 234

25 Zimmermann N, Cardoso CO, Moraes AL, Prando ML, Fonseca RP. Funções executivas e linguagem na infância: conceitos e relações entre componentes cognitivos para a interpretação neuropsicológica e neuropsicolinguística. In: Fonseca RP, Prando ML, Zimmermann N. Tarefas para avaliação neuropsicológica: avaliação de linguagem e funções executivas em crianças. São Paulo: Mennon; 2016:15-25

26 Chermak GD, Bellis TJ. Differential diagnosis of central auditory processing disorder and Attention-Deficit/hyperactivity disorder. In: Musiek FE, Chermak GD (Eds.). Handbook of (central) auditory processing disorder: auditory neuroscience and diagnosis. San Diego: Plural; 2014:557-590 
27 Gazzaniga MS, Ivry RB, Mangun GR. Neurociência cognitiva: a biologia da mente. Porto Alegre: Artmed; 2006

28 Lezak MD, Howieson DB, Bigler ED, Tranel D. Neuropsychological assessment (5th ed.). New York: Oxford University Press; 2012

29 Malloy-Diniz LF, Paula JJ, Sedó M, Fuentes D, Leite WB. Neuropsicologia das funções executivas e da atenção. In: Fuentes D, Malloy-Diniz LF, Camargo CHP, Cosenza RM (Org.). Neuropsicologia: teoria e prática. Porto Alegre: Artmed; 2014:115-138

30 Diamond A. Executive functions. Annu Rev Psychol 2013; 64:135-168

31 Brenneman L, Cash E, Chermak GD, et al. The relationship between central auditory processing, language, and cognition in children being evaluated for central auditory processing disorder. J Am Acad Audiol 2017;28(08):758-769

32 Cameron S, Glyde H, Dillon H, Whitfield J. Investigating the interaction between dichotic deficits and cognitive abilities using the dichotic digits difference test (DDdT) part 2. J Am Acad Audiol 2016;27(06):470-479

33 Gyldenkærne P, Dillon H, Sharma M, Purdy SC. Attend to this: the relationship between auditory processing disorders and attention deficits. J Am Acad Audiol 2014;25(07):676-687, quiz 706-707

34 Murphy CF, La Torre R, Schochat E. Association between top-down skills and auditory processing tests. Rev Bras Otorrinolaringol (Engl Ed) 2013;79(06):753-759

35 Murphy CF, Zachi B, Roque ECT, Ventura SD, Schochat E. Influência da memória, atenção, QI e idade em testes de processamento auditivo temporal: estudo preliminar. CoDAS 2014;26(02):105-111

36 Prando ML, Pawlowski J, Fachel JMG, Misorelli MIL, Fonseca RP. Relação entre habilidades de processamento auditivo e funções neuropsicológicas em adolescentes. Rev CEFAC 2010;12(04): 646-661

37 Riccio CA, Cohen MJ, Garrison T, Smith B. Auditory processing measures: correlation with neuropsychological measures of attention, memory, and behavior. Child Neuropsychol 2005;11(04): 363-372

38 Sanchez ML, Alvarez AMBMAvaliação das funções auditivas centrais e indícios de alteração de funções superiores. Revista eletrônica do World Congress on Brain, Behavior and Emotions. Porto Alegre, RS, Brasil 2017. Accessed March 09, 2019 at: http://www. brain2017.com/anais/index_int.php?

id_trabalho $=56814 \& a n o=2017 \& \mathrm{ev}=270 \#$ menuanais

39 Sharma M, Purdy SC, Kelly AS. Comorbidity of auditory processing, language, and reading disorders. J Speech Lang Hear Res 2009; 52(03):706-722

40 Stavrinos G, Iliadou V-M, Edwards L, Sirimanna T, Bamiou D-E. The relationship between types of attention and auditory processing skills: reconsidering auditory processing disorder diagnosis. Front Psychol 2018;9(34):34

41 Tomlin D, Dillon H, Sharma M, Rance G. The impact of auditory processing and cognitive abilities in children. Ear Hear 2015;36 (05):527-542

42 Wilson RH, Moncrieff DW, Townsend EA, Pillion AL. Development of a 500-Hz masking-level difference protocol for clinic use. J Am Acad Audiol 2003;14(01):1-8

43 Musiek FE, Shinn JB, Jirsa R, Bamiou D-E, Baran JA, Zaidan E. GIN (Gaps-In-Noise) test performance in subjects with confirmed central auditory nervous system involvement. Ear Hear 2005; 26(06):608-618

44 Musiek FE. Frequency (pitch) and duration pattern tests. J Am Acad Audiol 1994;5(04):265-268

45 Schochat E, Rabelo CM, Sanfins MD. Processamento auditivo central: testes tonais de padrão de frequência e de duração em indivíduos normais de 7 a 16 anos de idade. Pró-Fono Revista de Atualização Científica 2000;12(02):1-7

46 Santos MFC, Pereira LD. Teste de escuta dicótica com dígitos. Anais do I Congresso Paulista dos Distúrbios da Comunicação Humana São Paulo 1996

47 Pereira LD, Schochat E. Testes auditivos comportamentais para avaliação do processamento auditivo central. CD 3, faixa 2 . [Compact Disc]. Barueri: Pró Fono; 2011

48 Feniman M, Ortelan RR, Lauris JRP, Campos CF, Cruz MS. Proposta de instrumento comportamental para avaliar a atenção auditiva sustentada. Rev Bras Otorrinolaringol 2007;73(04): 523-527

49 Siqueira LS, Gonçalves HA, Pagliarin KC, et al. Teste Hayling Infantil: aplicação, registro, pontuação e dados normativos. In: Fonseca RP, Prando ML, Zimmermann N. Tarefas para avaliação neuropsicológica: avaliação de linguagem e funções executivas em crianças. São Paulo: Mennon; 2016:66-87

50 Sedó M, Paula JJ, Malloy-Diniz LF. O teste dos cinco dígitos. São Paulo: Hogrefe; 2015

51 Wechsler D. Escala Wechsler de inteligência para crianças - WISC IV: manual técnico. São Paulo: Casa do Psicólogo; 2013

52 Carim DB, Miranda MC, Bueno OFA. Tradução e adaptação para o português do Behavior Rating Inventory of Executive Function BRIEF. Psicol Reflex Crit 2012;25(04):653-661

53 Auditec. Masking level difference test. [Compact Disc]. Saint LouisAuditec Incorporated

54 Audiology Illustrated. Central auditory tests. Track 7. Frequency Pattern. [Compact Disc] Connecticut: Audiology Illustrated, LLC

55 Audiology Illustrated. Gaps in noise (GIN): full version. [Compact Disc]. ConnecticutAudiology Illustrated, LLC

56 IBM SPSS Statistics for Windows. (Version 22.0) [software]. Armonk, NY: IBM Corporation; 2013

57 Moore DR, Ferguson MA, Edmondson-Jones AM, Ratib S, Riley A. Nature of auditory processing disorder in children. Pediatrics 2010;126(02):e382-e390

58 Dias NM, Tortella G. Evidências de validade do teste de trilhas: partes A e B. In: Seabra AG, Dias NM (Orgs.). Avaliação neuropsicológica cognitiva: atenção e funções executivas. São Paulo: Mennon; 2012:67-74

59 Seabra AG, Reppold CT, Dias NM, Pedron AC. Modelos de funções executivas. In: Seabra AG, Laros JA, Macedo EC, Abreu N (Orgs.). Inteligências e funções executivas: avanços e desafios para a avaliação neuropsicológica. São Paulo: Mennon; 2014:39-50

60 Baddeley A. Working memory: theories, models, and controversies. Annu Rev Psychol 2012;63:1-29

61 Maerlender AC, Wallis DJ, Isquith PK. Psychometric and behavioral measures of central auditory function: the relationship between dichotic listening and digit span tasks. Child Neuropsychol 2004;10(04):318-327

62 Wilson WJ, Jackson A, Pender A, et al. The CHAPS, SIFTER, and TAPS-R as predictors of (C)AP skills and (C)APD. J Speech Lang Hear Res 2011;54(01):278-291

63 Springer SP, Deutsch G. Cérebro esquerdo, cérebro direito: perspectivas da neurociência cognitiva ( $5^{\underline{a}}$ ed.). São Paulo: Santos Editora; 2008

64 Weihing J, Guenette L, Chermak G, et al. Characteristics of pediatric performance on a test battery commonly used in the diagnosis of central auditory processing disorder. J Am Acad Audiol 2015;26(07):652-669

65 Isquith PK, Gioia GA. Behavior rating inventory of executive function - BRIEF. Interpretative Report. Florida: Psychological Assessment Resources, Inc; 2007 